\title{
Optimal Techniques for Cost Reduction and Control in Construction Sites
}

\author{
Sherif Mohamed Hafez ${ }^{1}$, Remon F. Aziz ${ }^{2}$, Hala Mostafa Mohamed Elzebak ${ }^{3}$ \\ ${ }^{1}$ Construction Engineering and Management, Structural Engineering Department, Faculty of Engineering, Alexandria University, Alexandria, \\ Egypt \\ ${ }^{2}$ Structural Engineering Department, Faculty of Engineering, Alexandria University, Alexandria, Egypt \\ ${ }^{3}$ M. Eng. Candidate Department of Civil Engineering, Alexandria University, Alexandria, Egypt
}

Email address:

hala.mustafa28@yahoo.com (H. M. M. Elzebak)

To cite this article:

Sherif Mohamed Hafez, Remon F. Aziz, Hala Mostafa Mohamed Elzebak. Optimal Techniques for Cost Reduction and Control in Construction Sites. Journal of Human Resource Management. Vol. 3, No. 3, 2015, pp. 17-26. doi: 10.11648/j.jhrm.20150303.11

\begin{abstract}
Despite the availability of various control techniques and project control software many construction projects still do not achieve their cost objectives . Research in this area so far has mainly been devoted to identifying causes of cost overruns. The earned value is a leading technique in monitoring and analyzing project performance and project progress. Although, it allows exact measurement of project progress, and can uncover any time and cost deviations from the plan, its capability in reporting accepted level of deviation is not well studied. There is limited research geared at studying factors inhibiting the ability of contractors to effectively control their projects. To fill this gap, a survey was conducted on 22 construction project organisations. It was noted that most project managers and contractors in Egypt find difficulty in controlling project costs due to problems which include Change order, Changes in the design, Errors in the design, current economic situation deterioration, Delay project and Rising prices of materials. The study was able to establish that the problem was actually not the techniques to use but rather the lack of knowledge of the techniques, the poor management of the cost control methodology, and the general poor site organisation and inadequate supervision. In addition, the main object of this study is to demonstrate the use of Activity Based Costing ( $\mathrm{ABC}$ ) approach as an alternative cost accounting system to the Traditional Cost Accounting System to determine the real and accurate cost of the projects. Activity Based Costing (ABC) prevents cost distortions which traditional cost accounting can not provide, this study presents an application of $\mathrm{ABC}$ and an example of applying $\mathrm{ABC}$ to construction projects. The conclusions of the study show that the application of $\mathrm{ABC}$ leads to better knowledge in tender pricing, more ability to estimate the cost and updating costs data. It also saves the suitable information which are necessary to enter the bidders and to compete to win them. This system helps in supervising and controlling the activities which the company do, and to make rational and correct decisions. The results of this study recommended that there is a need to change the traditional awarding system for contracts from the first lowest bidder to the most accurate one.
\end{abstract}

Keywords: Construction Management (CM), Earned Value Management (EVM), Target Cost (T.C), Value Engineering (V.E), Activity Based Costing (A.B.C)

\section{Introduction}

In construction almost all clients are interested in obtaining fully functional facilities completed in time, cost, quality and scope. A builder who is able to construct within the estimated time and budget, to the right standards and scope is an excellent builder. Cost control methodologies in structural engineering are of vital importance due to the alarming escalation of construction cost which needs to be effectively controlled. The research introduces the concept, needs and aims of cost control. It also visualizes the terms used and those involved in cost control work. The body of the research work centre on the reasons for increasing cost and the various steps taken to control this increase. Questionnaires were designed and administered to professionals within the construction industry which were analyzed and several deductions were derived from this analysis. Conclusion finding reveals that preparation of the cost control of project is highly important as it would help professionals in the construction field to maximize fund and use it effectively during project execution. The recommendations were that, 
the government should enact stable policies to strengthen the value of her local currency, the construction industries and the government should embrace the use of alternatively locally sourced materials that is less cheap than conventional building construction materials, avenue for soft loans at minimal interest rates should be made available for sub contractors by governments, Finally, the government should establish a regulatory body to carefully monitor the values of land cost at various locations in order to checkmate the excesses of the land owners that indiscriminately increase the sales of lands inappropriately that affects the total construction costs.

\subsection{Purpose of the Study}

To improve the predictability of capital project cost and schedule by establishing project controls systems to monitor and predict project outcomes. Effective control systems identify deviations from project plans and commitments early enough to eliminate surprises and allow corrective action.

\subsection{Background}

A project controls system should be established for each capital project. The scope and detail of the controls system should be based on the size, complexity, sensitivity, and execution strategy of the specific project. Each project controls system should include:

- A Cost Management Process that estimates, monitors, predicts, and reports project cost.

- A Planning and Scheduling Management Process that plans project activities, monitors completion of those activities, predicts timing of future activities, and reports schedule status.

- A Change Management Process that estimates the impact of change, enables and documents the change decision, and integrates the change into the project scope of work.

\section{Literature Review}

In Egypt, there are some serious challenges facing the construction sector. Being one of the major sectors in the Egyptian economy, construction and building sector has a significant impact on GDP, employment and investment contributing to at least $4.7 \%$ of the total GDP (Amcham 2003), (ISCG 2010). However, in the last two years and after the Egyptian revolution, many sectors suffered due to the unstable economy situation associated with the political risks in Egypt (Aref 2012). The construction sector has seen decline with $9.4 \%$ in the 1st Quarter of the Year 2012 and it continued to suffer the impacts of the unstable political situation (Aref 2012). This contraction, if continued, would have a deep impact on unemployment rates and many other industries. The main factors that are affecting the Egyptian construction sector can be classified as follows: construction companies, government policies and strategies, available resources, institutional backing and supporting industries
(Amcham 2003). The prices and cost of the construction production factors such as labour, materials, machine utilization, transport, energy and other cost have changed over time, especially after the revolution.

Cost Control as defined by Neil J.M. (1982) is the processing of raw information received from projects, operating divisions, and special staff division and relating this information to various project cost estimates and schedules for the purpose of presentation of results in the form of reports to all levels of company managerial, the client and outside agencies. According to Nunnally (1998), cost control of a project involves the measuring and collecting the cost record of a project and work progress. It also involves the comparison of actual progress with the planning. The main object of cost control of a project is to gain the maximum profit within the designated period and satisfactory quality of work.

\section{Methodologies}

\subsection{Traditional Cost Management}

Traditional cost management focuses on products. It is a process that real project product cost is calculated on the foundation of Confirmation and calculation quantity of resources consumed.

The Earned Value Management System (EVMS), sometimes referred to as Cost/Schedule Control Systems Criteria, is an extension of the time-cost envelope principle. Originally developed by industrial engineers to gauge plant output performance, EVMS compares the physical work plashed to date with both the actual cost expenditure and the planned work to be accomplished. This three-dimensional comparison determines the earned value on a project and forms the basis for a more accurate projection of final project cost than can be calculated simply by contrasting actual costs with planned.

\subsection{EVM Measures}

EVM consists of the following primary and derived data elements. Each data point value is based on the time or date an EVM measure is performed on the project.

\subsection{Primary Data Points}

- Budget At Completion (BAC)

- Total cost of the project.

- Budgeted Cost for Work Scheduled (BCWS) / Planned Value (PV)

- The amount expressed in Pounds (or hours) of work to be performed as per the schedule plan.

- $\mathrm{PV}=\mathrm{BAC} * \%$ of planned work.

- Budgeted Cost for Work Performed (BCWP) / Earned Value (EV)

- The amount expressed in Pounds (or hours) on the actual worked performed.

- $\mathrm{EV}=\mathrm{BAC} * \%$ of Actual work

- Actual Cost of Work Performed (ACWP) / Actual Cost 
$(\mathrm{AC})$

- The sum of all costs (in Pounds) actually accrued for a task to date

\subsection{Derived Data Points}

Cost forecasting:

- Estimate At Completion (EAC)

- The expected TOTAL cost required to finish complete work.

- $\mathrm{EAC} 1=\mathrm{ACWP}+(\mathrm{BAC}-\mathrm{BCWP}) / \mathrm{CPI}$

- $\mathrm{EAC} 2=\mathrm{ACWP}+(\mathrm{BAC}-\mathrm{BCWP}) /(\mathrm{CPI} \times \mathrm{SPI})$

Here atypical means it is assumed that similar variances will not occur in the future.

- Estimate to complete (ETC)

- The expected cost required to finish all the REMAINING work

- $\mathrm{ETC}=\mathrm{EAC}-\mathrm{AC}$

- $=(\mathrm{BAC} / \mathrm{CPI})-(\mathrm{EV} / \mathrm{CPI})$

$\cdot=(\mathrm{BAC}-\mathrm{EV}) / \mathrm{CPI}$

Variances:

- Cost Variances (CV)

- How much under or over budget.

- $\mathrm{CV}=\mathrm{EV}-\mathrm{AC}$

- NEGATIVE is over budget, POSITIVE is under budget.

- Schedule Variances (SV)

- How much ahead or behind schedule.

- $\mathrm{SV}=\mathrm{EV}-\mathrm{PV}$
- NEGATIVE is behind schedule, POSITIVE is ahead of schedule.

- Variance At Completion (VAC)

- Variance of TOTAL cost of the work and expected cost.

- $\mathrm{VAC}=\mathrm{BAC}-\mathrm{EAC}$

Performance indices:

- Cost Performance Index

- $\mathrm{CPI}=\mathrm{EV} / \mathrm{AC}$

- Over $(<1)$ or under $(>1)$ budget.

- Schedule Performance Index

- $\mathrm{SPI}=\mathrm{EV} / \mathrm{PV}$

- Ahead $(>1)$ or behind $(<1)$ schedule.

\section{Alternative Methods of Cost Control}

It is necessary to decide which control is required and amount of detail that will be in entered into the construction stage. Many cost control methods have been used in the past in different companies and have not survived. The cost itself is a major difficulty in operating a detailed cost control system. It is an expensive operation in the time of cost clerks, etc, for a large contract to carry out a detailed cost control system. There are new three types of cost control system; they are Target cost, Activity based cost and Value engineering. A comparison between those methods and traditional method is shown in table (1).

Table 1. Comparison Between traditional Cost Control Methods and modern cost control method.

\begin{tabular}{|c|c|}
\hline Modern Construction project cost mamngment & Traditional method \\
\hline $\begin{array}{l}\text { Controlling cost to prevent wasteful and loss in all activities using financial indicators to } \\
\text { achieve the cost reduction but with low importance the role of standards Financial indicators } \\
\text { as methods for control and increasing importance of standards non-financial indicators such } \\
\text { as: quality, customer satisfaction degree, the extent of exploitation } \\
\text { Space available }\end{array}$ & $\begin{array}{l}\text { Controlling cost to prevent wasteful and loss in all activities } \\
\text { using financial indicators to ensure the reduce costs; }\end{array}$ \\
\hline Application of just in time method (JIT) to construction project & $\begin{array}{l}\text { Saving correct basice to evaluate inventory last the } \\
\text { financial period }\end{array}$ \\
\hline $\begin{array}{l}\text { Application of Activity based costing method to construction project } \\
\text { (1)The management is meticulous and deepgoing. It is easier to find existing problems in } \\
\text { the management } \\
\text { (2)Cost information is complete and accurate. } \\
\text { (3)Cost control object is more centralized and helpful to control cost and improve } \\
\text { management from the beginning. } \\
\text { (4)It is helpful for company to establish their own cost forecast tools. } \\
\text { (5)It is helpful for construction company to adapt to market development pattern in future. }\end{array}$ & $\begin{array}{l}\text { Compilation of cost elements according to one of two } \\
\text { methods: } \\
\text { Production orders or production stages }\end{array}$ \\
\hline $\begin{array}{l}\text { controlling costs during all stages of the project life cycle from the beginning Design stage, } \\
\text { where } 80 \% \text { of product costs determined during this Stage }\end{array}$ & Controlling cost after the manufacturing stage \\
\hline reducing the standard cost to be accessible continuously & $\begin{array}{l}\text { Compared with the current results that obtained standard is } \\
\text { set Previously and identifying deviations, analysis and do } \\
\text { Corrective action to ensure compatibility with future results } \\
\text { The estimated results. }\end{array}$ \\
\hline
\end{tabular}

\subsection{Target Cost (T.C)}

Target costing in the construction industry is the practice of constraining design and construction of a capital facility to a maximum cost. Research (Implementing Target Costing, by The Society of Management Accountants of Canada) defines it as an appropriate practice for all clients with financial constraints that a capital facility project must meet in order to be considered successful by that client. Target cost is a management approach that drives design to deliver to defined customer values within project constraints. 


$$
\text { Selling price }- \text { desired profit }=\text { target } \cos t
$$

The customer sets the price

Profit must be achieved through cost control

Target Costing Characteristics

[1] Contradicts the traditional approach: design product, determine cost, set price

[2] Intense customer focus

What do they want?

How much will they pay for it?

Can we make a profit on it?

[3] Want answers to these questions before committing to the project

[4] Cost control from the beginning

- $70-90 \%$ of costs are committed to at the design stage

- Focus on product and process design to engineer out costs from the beginning

»Saves costly changes later on

[5] Product, manufacturing process, delivery process designed simultaneously

- Ensures features customers demand, but within acceptable cost parameters

- Eliminates the temptation to add costly features

»Customers may not value the added features

- Forces consideration of manufacturability

$»$ Reduces the need for subsequent changes

[6] Cost control at all phases of the product life cycle

- Design

- Production Delivery/setup

- Customer's cost of ownership

»Emphasizes future sales instead of current cost savings

- Service and repair

- Disposal and recycling

\subsection{Value Engineering (VE)}

- Value engineering is a balance between cost and quality in order to achieve the desired function.

- Value Engineering is Min. Max. Proactive Approach

- Min. Cost Max. PerformanceV : f (P,C)V : Value P : Performance $\mathrm{C}$ : Cost

Value Engineering (VE), also called: Value Management

- Value Analysis

- Target costing

VE is a powerful systematic approach to analysis \& improve the value within certain performance, through continuous improvement process.

$\mathrm{VE}$ is a professional, function oriented, creative and systematic team management approach, used to analyze and improve value.

VE encourages relationship between construction and design.

VE differs from other cost-reduction activities in that it is function oriented, as it involves a searching analysis of the function of a product as opposed to just seeking lower costs in methods and processes to produce the same product.

Why Value Engineering?

- Maximize performance (quality, safety, time, etc.)
- Maximize value added

- Minimize cost

- Good communication management

- Good project management information system (PMIS)

- Good team approach

- $\mathrm{VE}=$ Value improvement $\&$ minimum cost

What is the value?

"Value" = The measurement of how well an item fulfills its function, considering:

- Function or performance level

- Quality level

- Safety level

- Unused capacity

- Revenue, .. etc.

"Function" = The characteristic of an item which meets the need or want of the user

- "Basic function" = The feature or characteristic which is the primary reason for the existence of an item, from the user's point of view

- "Secondary function" = A feature which supports the basic function. It may make the item "sell" better or work better. i.e. it does not contribute directly to the accomplishment of a basic function.

The Value Engineering process determines possible ways of eliminating unnecessary expenses, while assuring that the quality, reliability, performance, consistency and other critical factors will meet the client's satisfaction (Dell' Isola, 1997).

VE is simply a systematic use of techniques which

- Pre-study preparation phase:

- VE-study phase:

- Post VE-study phase:

I- Pre-study preparation phase:

- Awareness (training, benchmarking, .. etc)

- Project selection

- Team selection

- Study scope of work

- Data gathering

II- VE-study phase:

- Information analysis

- $\mathrm{ABC}$ analysis (rule 80/20)

- Select the required items

- Determine the required function of an item,

- Function analysis (identify values for this function)

- Value analysis

- Establish the functions at the lowest overall cost without sacrificing quality, performance or safety.

- Evaluation \& risk assessment

- Presentation

III- Post VE-study phase:

- Final presentation

- Final report

- Target plan

- Implementation

- Review \& follow-up

"Continuous improvement process

Evaluation Parameters 
1. Goals \& target \& constraints

2. Leadership \& org. structure

3. Change management

4. PMIS documentation

5. Cost plans

6. Job plans

7. Quality plans

8. Safety plans

9. Material plans

10. Standards \& codes

11. Negotiation skills

12. Planning skills

13. Control skills

14. Risk assessment skills

15. Value engineering skills

16. Problem solving skills

17. Others skills

The main objective of implementing Value Engineering is to improve the desired value by the use of all available resources while eliminating unnecessary costs, without sacrificing quality, performance, function or safety.

\subsection{Activity Based Costing (ABC)}

$\mathrm{ABC}$ is a relatively recent innovation in cost accounting, it is rapidly being adopted by companies across many industries and within government and not-for-profit organizations. ABM is a useful approach to understand a sequence of activities, differentiate between value and nonvalue, and eliminate the wasteful activities. Similarly with $\mathrm{ABC}$, it is an analytical approach to better identify costs to products in situations where that is difficult. Others (Askarany\&Yazdifar, 2007) consider that $\mathrm{ABC}$ and ABM have not been highly diffused among practitioners and that is why practitioners are having doubts in terms of replacing traditional techniques

Steps in development of an ABC System

$\mathrm{ABC}$ uses cost drivers to assign the costs of resources to activities and unit cost as a way of measuring an output .There are four steps to implementing $\mathrm{ABC}$ :

[1] Identify activities

[2] Assign resource costs to activities

Direct - costs Indirect - costs

General/administration costs

[3] Identify outputs.

[4] Assign activity costs to outputs.

\section{Questionnaire}

A questionnaire survey That was carried out to gather information from technical professionals who are involved in the construction industry. It is to get the opinion and understanding from the experienced respondents regarding the cost control.

For the purpose of achieving the goal of this research, a questionnaire was designed and administrated in a lot of the leading construction companies in Egypt. This questionnaire was used to investigate the main factors impacting the construction projects Problems face by contractors in controlling the costs on site in the Egyptian construction industry and The understanding of contractors in cost control system in construction. Based on this questionnaire and the literature survey, the problem statement was better formulated.

\subsection{Structure of the Questionnaire}

The key purpose of this survey is to identify the contractors 'understanding regarding the cost control thinking/techniques in the Egyptian construction industry. The questionnaire is classified into 3 main sections as follows:

- Section (A): is structured to identify the factors affecting the overall cost control performance of the project in current practice and the methods adopted to reduce these negative impacts.

- Section (B): is structured to understanding of contractors in cost control system in construction .

- Section (C): is structured to examine the respondents' awareness about cost control techniques and their reporting system in the Egyptian construction industry.

\subsection{Data Analysis and Documentation}

The data collected from the survey was analyzed using Microsoft office excel and "relative Indices" (RI) technique. Presentation was in the form of graphs, bar charts, and tables. The RI technique was used by Holt et.al. (1996) in the same context of application using the formula:

$$
\mathrm{RII}=\sum \mathrm{W} / \mathrm{A} \times \mathrm{N}
$$

where $\mathrm{W}$ is the weight given to each factor by the respondents and ranges from 1 to $5 ; \mathrm{A}-$ the highest weight $=$ 5; $\mathrm{N}$ - the total number of respondents Table 2. illustrates the top significant factors affecting the performance of construction projects. It can be inferred from this table that 3 most important factors according to the perception of consultant, and contractor are: average delay because of closures leading to materials shortage, unavailability of resources, and leadership skills for project manager.

Table 2. The top significant factors affecting the performance of construction projects.

\begin{tabular}{lll}
\hline Rank & RII & Factors \\
\hline 1 & 99.7 & Change order \\
2 & 99.3 & Changes in the design \\
3 & 99 & Errors in the design \\
4 & 98 & current economic situation deterioration \\
5 & 97 & Delay project \\
6 & 95 & Rising prices of materials \\
\hline
\end{tabular}

\subsection{Contractors Understand}

- $50 \%$ of the respondents are aware about cost control concept and $36.5 \%$ of the respondents have scarcely aware of it. 


\subsection{Cost Control Reporting from Contractors View}

- $68 \%$ of the respondents with experience more than 15 years have high potentials to use the profitability of the work while $18 \%$ of the respondents with experience above 10 years use the units cost. Only $13 \%$ of the respondents with experience between 5-10 years use the efficiency system.

\subsection{Develop Mitigating Measures}

Following the analysis of the survey results, the identified top project control inhibiting factors were investigated in greater depth by interviewing experienced practitioners in a bid to find out the reasons why they make project control more difficult. This subsequently leads to the development of a list of measures that can be used to mitigate these factors. This stage of the study was achieved through a series of indepth interviews. The top six inhibiting factors were selected as the main focus because of their importance and the fact they are common for cost control.

- Preventive measures: These are precautionary measures that are put in place as a defense to the inhibiting factors.

- Predictive measures: these may seem similar to preventive measures but they are not the same. Predictive measures are put in place in order to spot potential problems to the control process in the future so that they can be stopped from happening or be prepared for them should they happen.
- Corrective measures: these are measures that are utilized to mitigate the effect of the project control inhibiting factors by acting as a remedy. These measures are reactive measures that only act after the event.

- Organizational measures: These measures generally encompass practices that go wider than the actual control process but have an effect on project control.

\subsection{Good Practice Checklist}

The developed good practice checklists are an integral part of the PCIM model. They were developed through a three staged research process, involving

(1) literature review;

(2) questionnaire survey, analysis and synthesis; and finally

(3) semi-structured interviews with practitioners to ensure the practical relevance of the developed checklists by drawing from the real life experiences of interviewees.

\section{Case Study}

\begin{tabular}{ll}
\hline Project location & $\begin{array}{l}\text { : kafr El-shiekh university Faculty of } \\
\text { Dentistry }\end{array}$ \\
\hline Plot area & $: 3,000 \mathrm{~m} 2$ \\
Contract signing date & $: 20 / 02 / 2013$ \\
Project completion date & $: 15 / 02 / 2015$ \\
Project consist of & $:$ five different Floors and Amphitheater \\
& buildings four typical floors. \\
\hline
\end{tabular}

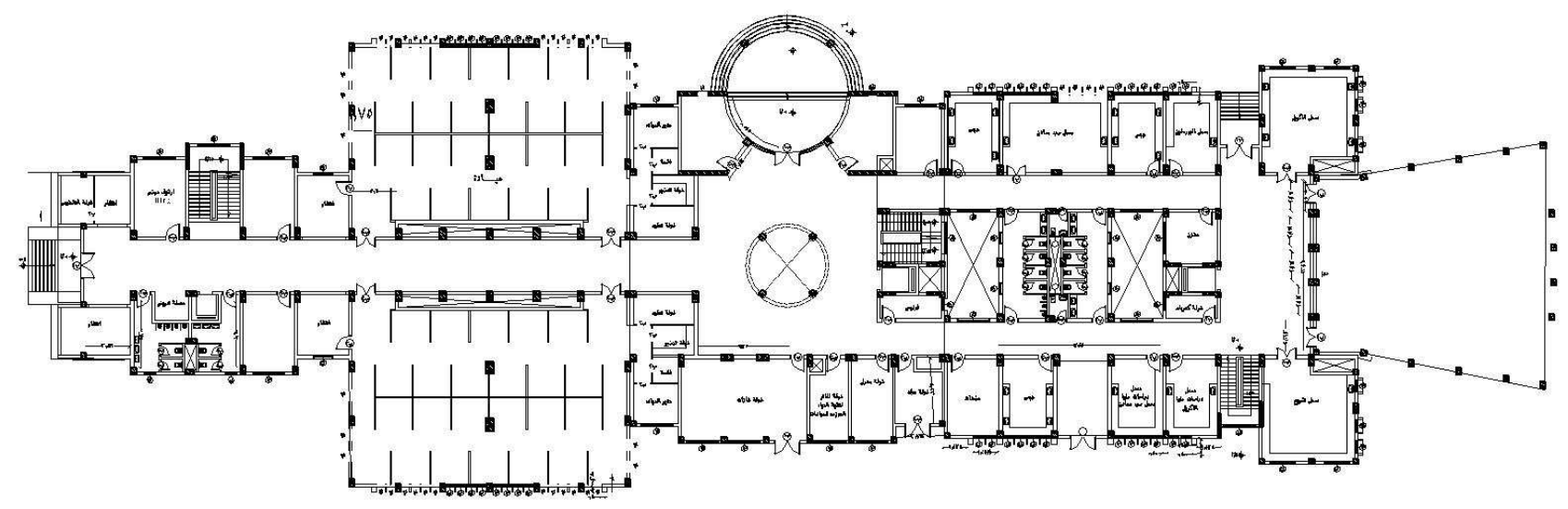

Figure 1. Project Plan of building (1).

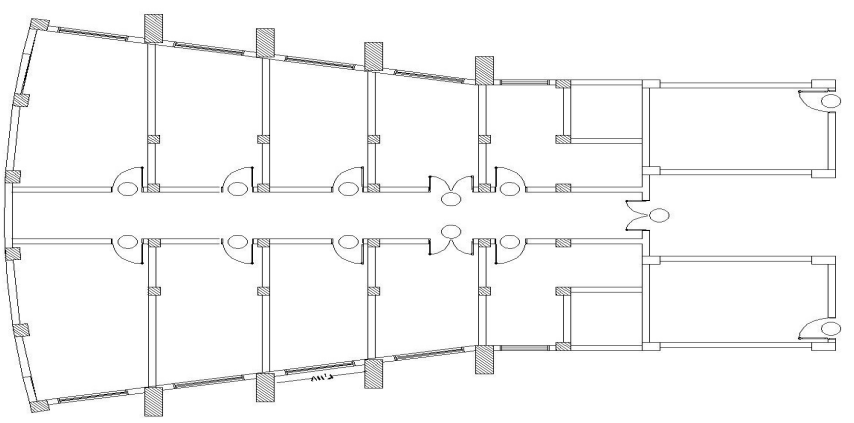

Figure 2. Project Plan of building (2). 
Method Activity Based Costing

Theoretically ABC is based on a "flow view" of production theory in at least two ways: First, process-based costing assumes that resources are assigned to activities (processes) and activities (processes) are assigned to pieces of projects whereas resource-based costing assumes resources are directly assigned to pieces of projects/ products.
Second, the purpose of process-based costing is not only preventing a cost distortion but also providing a process view, thereby helping reduce or eliminate wastes or non-valueadded activities. In conclusion, construction project control can encompass the cost control by adopting an activity-based costing system. Traditional allocation method

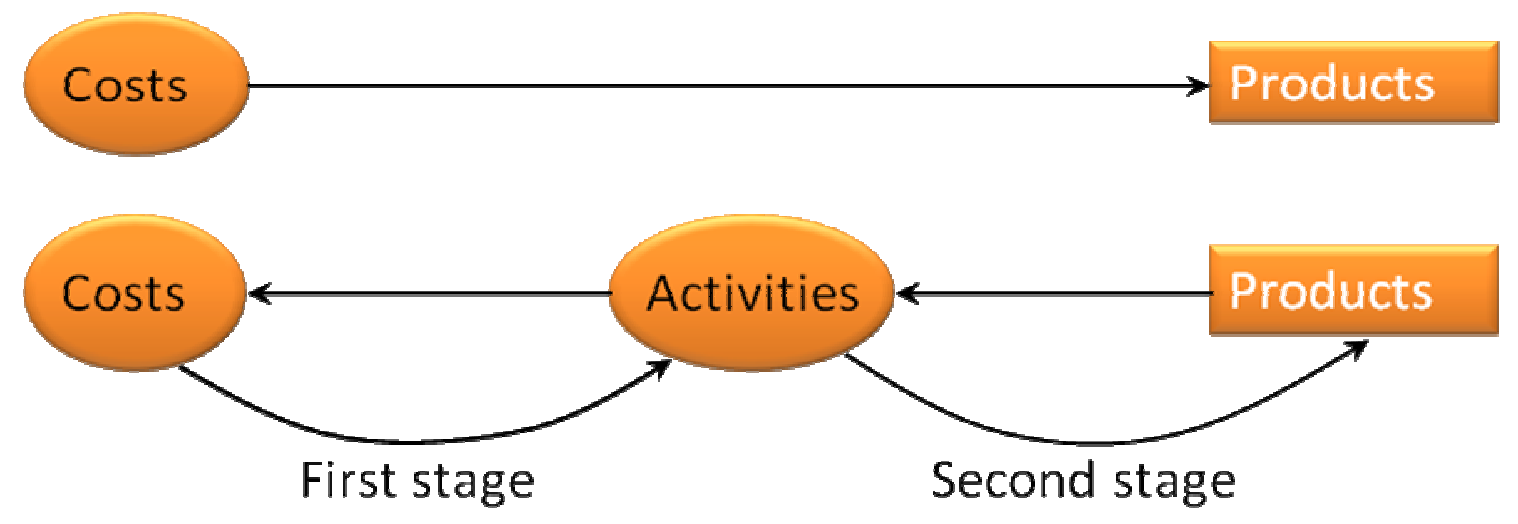

Figure 3. Activity-based allocation method.

Step 1 - Plan the system

What are the goals?

- Inventory valuation

- Process improvement

- Foster active involvement

- Assemble cross-functional team

- Functional specialists

Problem Identification

The characteristics of current practice in controlling overhead costs are described as follows:

- Costs are assigned directly to accounts which are resources (employees).

- Project overhead costs are not distributed or allocated to different cost objects such as specialty contractors or work divisions.

- Home office overhead costs are allocated to projects based on the amount of contract. (This information is acquired from the interview with a cost engineer at
DPR head office)

The following problems are identified through discussion with managements:

- Even though in altered environments overhead costs have become more important than before, the management of overhead costs, costs for nonproduction sector, has not been given enough attention. As a result, the function of supporting activities has also not been given enough attention.

- Since the current volume-based allocation of overhead costs does not provide accurate allocation to cost objects such as projects or work divisions, the company hardly gets accurate information on profit relationships with clients and specialty-contractors.

- The cost reports on overhead costs include information on costs for each resources, but lack information on relationship with other project participants such as clients specialty-contractors.

Table 3. Cost details for Build 1 and build 2 based on Company study of company.

\begin{tabular}{llllll}
\hline & Direct cost & & Bild1 & Bild2 & Total \\
\hline \multirow{3}{*}{ First } & 01 & Material & 15107564.26 & 3787548.93 & 18895113.19 \\
& 02 & Equipment & 543574.1 & 50858.57 & $594,432.67$ \\
& 03 & Labor & 4218909.752 & 517281.699 & 4736191.451 \\
& 04 & Subcontractor & $6,550,898.8$ & 785822 & $7,336,720.80$ \\
\multirow{3}{*}{ Second } & Sum of direct cost & 31562458 & & 5049994 \\
& Tax & 4227352 & 822641.8 & $3,818,588$ \\
& Indirect cost & 2795315.553 & 1023272.447 & \\
Third & First + second & Indirect cost & 36612452 & & \\
Fourth & Total cost & $3,818,588$ & & \\
\hline
\end{tabular}


Step 2 - Define, analyze activities and resources

D Decompose organization into elemental activities

Who does what, and why?

- Interview employees

- Determine resources

- Determine inputs and outputs

- Gather statistics on activities

- Inputs and outputs

- Transaction, duration, intensity

- For possible use as second-stage cost drivers

All tasks consuming overhead resources are grouped into tweleve major business activities. This relatively low number of activities chosen is a reflection of the modest level of accuracy that is required. This simplification is also intended to focus the reader's attention more on methodology than on accounting details. A company looking for a higher level of accuracy from its costing system would be required to use a higher number of activities.
Table 4. Overhead Expense Categories.

\begin{tabular}{ll}
\hline $2,875,550$ & 1- Local Personnel (Excluding Housing) \\
\hline 358,368 & 2- Personnel Transport \\
69,390 & 3- Office \& Surveying Equipment \\
28,800 & 4- Office Supplies \\
19,000 & 5- Telephone \& Communication \\
57,300 & 6- Miscellaneous Expenses \\
126,340 & 7- Site Installations \\
46,140 & 8- Safety Requirements \\
22,300 & 9- Clinic Supplies \\
20,000 & 10- Mobilization \& Demobilization \\
20,000 & 11- General Site Equipment \\
20,000 & 12- Engineering Services \\
12,000 & 13- Quality Control \\
$143,400.00$ & 14- Housing for Staff \\
$3,818,588$ & Total Amount-Indirect In L.E. \\
\hline
\end{tabular}

Table 5. Activity Pools and Activities Defined for two builds (based on ABC).

\begin{tabular}{llllllll}
\hline \multirow{2}{*}{ Total cost } & Labor cost & \multicolumn{2}{l}{ Total quantity } & & Quantity & \multirow{2}{*}{ Cost driver } & \multirow{2}{*}{ Activity pools } \\
\cline { 2 - 3 } & Build 2 & Build 1 & & Build 2 & Build 1 & M3 & Excavation \& backfilling \\
& 0 & 0 & 19300 & 2800 & 16500 & replacement \\
10000 & 10000 & 0 & 5521 & 321 & 5200 & M3 & Concrete works \\
1832025 & 197921 & 1634103 & 26905 & 1863 & 25042 & M3 & Frames works \\
79097 & 79097 & & 244 & 244 & & M3 & Finishing works \\
1593574 & 119257 & 1474317 & 56460 & 7120 & 49340 & M2 & Opining works \\
0 & 0 & 0 & 9238 & 70 & 9168 & M2 & Tiles works \\
952291 & 14576 & 937714 & 11300 & 600 & 10700 & M2 & Wood cladding \\
162444 & 57251 & 105193 & 8127 & 4248 & 3879 & M2 & Gypsum board works \\
7731 & 185 & 7546 & 7500 & 800 & 6700 & M2 & insulation \\
83036 & 35997 & 47039 & 20850 & 5550 & 15300 & M2 & Water supplies \\
190814 & 80174 & 110640 & 357.00 & 150.00 & 207.00 & Washes no. \\
45034 & 19997 & 25037 & 24342.00 & 9132.00 & 15210.00 & Light unites no. & Elec. Works \\
\hline
\end{tabular}

The overhead rates developed in Table 5.can now be used to assign process costs to cost objects as shown in Table 6 .

Step 3 - Establish activity cost pools and determine first stage allocation

- First stage allocations assign costs to cost pools

- Requires costs to be re-categorized according to why they are incurred, not by type

- Drivers may be employee time, square footage, etc.
Step 4 - Determine second stage drivers and assign costs to cost objects

- Outputs of activity analysis may be second stage drivers

- Distance moved, times handled, machine hours, units, etc.

- Amount assigned to the cost object is the amount of activity consumed times the rate per unit of the activity

Table 6. Indirect Costs and Determination of the First Stage Cost Drivers (based on ABC).

\begin{tabular}{|c|c|c|c|c|c|c|c|c|}
\hline \multirow{2}{*}{$\begin{array}{l}\text { Cost } \\
\text { Build2 }\end{array}$} & \multirow{2}{*}{ Cost Build 1} & \multirow{2}{*}{$\begin{array}{l}\text { Loading } \\
\text { Rate }\end{array}$} & \multirow{2}{*}{ Total } & \multicolumn{2}{|c|}{ Causative cost no. } & \multicolumn{2}{|l|}{ Causative cost } & \multirow{2}{*}{ Activity pools } \\
\hline & & & & Build 2 & Build 1 & Wave & Labor cost & \\
\hline 0 & 0 & 0 & 19300 & 2800 & 16500 & Soil works & 0 & Excavation \& backfilling \\
\hline 448 & 7257 & 1 & 5521 & 321 & 5200 & Replacement & 7705 & replacement \\
\hline 97741 & 1313817 & 52 & 26905 & 1863 & 25042 & Concrete works & 1411558 & Concrete works \\
\hline 60944 & 0 & 250 & 244 & 244 & 0 & Frames & 60944 & Frames works \\
\hline 154839 & 1072996 & 22 & 56460 & 7120 & 49340 & Finishing & 1227835 & Finishing works \\
\hline 0 & 0 & 0 & 9238 & 70 & 9168 & Doors and windows & 0 & Opining works \\
\hline 65422 & 59739 & 15 & 8127 & 4248 & 3879 & cladding & 125161 & Wood cladding \\
\hline 635 & 5321 & 1 & 7500 & 800 & 6700 & Ceilings & 5956 & Gypsum board works \\
\hline 17030 & 46948 & 3 & 20850 & 5550 & 15300 & Isolate works & 63979 & insulation \\
\hline 61773 & 85247 & 412 & 357 & 150 & 207 & Draiange & 147020 & Water supplies \\
\hline 13017 & 21681 & 1.425 & 24342 & 9132 & 15210 & Elec. & 34698 & Elec. Works \\
\hline
\end{tabular}

$\mathrm{OH}$ Rate $=$ Overhead/Direct Labor Hours(Quantity)

Electrical works : $34698 / 24342=1.425$ per unit 
A comparison of costs for providing build 1 and build 2 labor, delivery, andservices under the tradition costing and

activity-based costing systems is shown on Table 7.

Table 7. Comparison of the Costs of build 1 and build 2, based on Traditional Costing and ABC Systems.

\begin{tabular}{lllllll}
\hline & Build1 & \multicolumn{5}{c}{ Build 2 } \\
\hline & Study of company & abc & various & Study of company & abc & various \\
Total cost & 31301882 & 31822045.63 & -520163.6 & 11458582.3 & 10938418.68 & 520163.6 \\
\hline
\end{tabular}

\section{Conclusion}

The main objective of this research was to improve the overall performance of construction building projects in Egypt by applying the appropriate management approach to the process from the Contractor perspective. This target was achieved by developing a proposed cost control Construction Framework. This framework is considered as a cost control implementation guideline. This framework was developed based on 3 foundations: 1) Literature survey to investigate the benefits of using cost control approach in construction 2) Questionnaire in different construction projects in Egypt to evaluate the factors affecting projects' performance, measure the awareness of engineers about cost control construction and evaluate their concerns about the main cost control principles 3) Modern Project Control approach and its effect on the construction process being a reactive approach. The developed framework consists of four components: 1) cost control method in a construction project. 2) Used Modern cost control tools/techniques 3) main problem faced by the contractor in controlling the costs on site 4) Qualified expertise. To verify the developed Framework, it was implemented on Case Study in Egypt. A customized simulation model was developed in Excel to show the effect of the activity based costing concepts on the project cost control for part of the works described in the framework.

\subsection{Findings of the Report}

The Framework results showed how various aspects of cost control thinking can be implemented in a construction project such as activity based costing method. This method was applied on a case study in Egypt showing the impact of using activity based costing concepts on the cost of the over head activities. The key is to understand that a model for cost and value management in projects involves a systematic, lifecycle philosophy based on their integration and used as an ongoing feature. Therefore, cost control principles and tools can be applied to construction industry to control the outcomes through the control of the entire production processes. The implementation of cost control approach on the construction process managed to reduce the overall duration of the process by improving the way of management. Being adopted in similar countries, cost control construction can be applied in construction projects in Egypt by increasing the awareness of the engineers about this approach.

\subsection{Recommendations}

Construction tasks are expensive and frequently cause in arguments and claims, which generally affects progress of construction projects. The environment of construction organizations should be suitable to implement projects with successful completion. In the construction industry, it is necessary to find the weaknesses of particular task in order to solve and overcome them. Mentioned below are the recommendations which were found to be important factors for improving cost control in the construction industry.

- A detail schedule of material supply schedule for each project should be provided by the contractors. It should contain the time required to supply materials and the availability of the local market to furnish the required materials in time. Extra attention is required on quality of construction materials and tools used in their projects because using suitable materials and tools reduces both the time taken to finish the work and wastage of materials.

- Organizations should make sure there is enough lighting present at the construction sites which can indirectly reduce the number of accidents. Continuous safety training and meetings should be arranged to achieve better performance in labor productivity.

- Purchased material should be stored at appropriate location and should be easily accessible and close to constructed buildings to avoid wasting labor time for multiple-handling materials.

- To achieve desired results, time required to implement change orders and to make corrections in drawings and specifications should be estimated and scheduled without affecting the project-time completion. Regular meetings should be arranged with the project authorities.

- Various external and natural factor risk should be considered in the budget estimation to minimize delays due to closures and material shortages. There should be suitable emergency budget to cover cost of increased material.

- A financial incentive in the form of best employee of the year should be implemented to create competition among the employees, thus achieving better productivity.

- Complex design and incomplete drawings should be avoided and care should be taken to avoid confusion among the various construction agencies.

- Change orders and design error should be avoided as 
much as possible. These factors can be costly and time consuming if the work has been done. Work sequences can also be affected due to rework.

\subsection{Future Research}

This thesis identified main guidelines for applying Activity based costing approach in construction through a proposed framework. Further research is required to show the impact of using overhead control approach on the overall cost and productivity of a project. Also, the proposed framework should be applied to different kinds of project to show the amount of contributory and non-contributory activities in different project types. In addition, this framework should be further tested at site level in Egypt by conducting action research in different project types.

\section{References}

[1] Adrian, J. (1987). Construction Productivity Improvement. Elsevier Science Publishing, Amsterdam, Netherlands.

[2] Aref, A. (2012). Construction Blues. Business Today Egypt .

[3] Australia, E. (2012). Recommended Practices for the Application of Activity based costing Methods to Building New Australian LNG Capacity.
[4] Baccarini, D. (1996). The concept of project complexity-a review. International Journal of Project Management Vol. 14, No. 4, pp. 201-204

[5] Ballard, H. G. (2000). The Last Planner System of Production Control. Faculty of Engineering, The University of Birmingham.

[6] Mostafa E. Shehata, K. M.-G. (2011). Towards improving construction labor productivity and projects' performance. Alexandria Engineering Journal 50, 321-330 .

[7] Olawale, Y. A., \& Sun, M. a. (2010). Cost and Time Control of Construction Projects:Inhibiting Factors and Mitigating Measures in Practice. Construction Management and Economics, 28 (5), $509-526$.

[8] Peter Andrejev, C. C. (2012). Improving Complex Facility Construction Projects by Using an "Owner's Paladin".

[9] PMI. (2008). A Guide to the Project Management Body of Knowledge (PMBOK® Guide) - Fourth Edition. PMI.

[10] Refaat H. Abdel-Razek, H. A.-H. (2007). Labor productivity: Benchmarking and variability in Egyptian projects. International Journal of Project Management 25,189-197 .

[11] Reginato, J. M., \& Graham, S. T. (2011). Implementing the Last PlannerTM System in Large Public Lump Sum Bidding for Building Projects. 47th ASC Annual International Conference Proceedings. 